\title{
Experimental Analysis on Seismic Behavior of Prefabricated Reinforced Concrete Column to Steel Beam Exterior Joints with Ribbed Angle Steel
}

\author{
Z.H. Zhang ${ }^{1, *}$, G.X. Mao ${ }^{1}$, Y. Liu ${ }^{2}$, A.L. Xiao ${ }^{3}$ and Z.L. Liu ${ }^{4}$ \\ ${ }^{1}$ College of Civil Engineering, Hunan City University, YiYang, 413000, China \\ ${ }^{2}$ Taiyuan University, Taiyuan, 030000, China \\ ${ }^{3}$ Zhongmin Zhuyou Technology Co., Ltd,Changsha, 410000 China \\ ${ }^{4}$ Department of Civil Engineering, University of Auckland, Auckland 1010, New Zealand
}

Received 2 May 2021; Accepted 1 July 2021

\begin{abstract}
Basic structural forms of reinforced concrete column-steel beam composite joints, such as beam- and column-through structures, are difficult to construct due to their complex structure. A joint connection construction method based on the ribbed angle steel was proposed in this study to improve construction performance of such joints, and the industrial assembly construction between reinforced concrete columns and steel beams was realized. By carrying out low cyclic loading test and numerical simulation of three full-scale specimens, the influence of beam-column section,the number of bolts between assembly connectors and steel beams on the performance of joints was examined by carrying out low cyclic loading test and numerical simulation of three full-scale specimens. Moreover, failure mode of joint was analyzed in detail and seismic performance indexes, such as bearing capacity, hysteretic performance, ductility, and energy dissipation capacity of joints, were compared. The results reveal that for different resistance matching among columns, beams, and connectors with ribbed angle steel, there are three failure modes of the joints, namely, shear failure in core area, slip at beam end, and slip at beam end with shear failure in core area. Seismic performance of joints varies with their failure modes. Hysteretic curve of shear failure joint in the core area shows evident pinch phenomenon. Ductility and equivalent viscous damping coefficients are 2.026 and 0.11 , respectively. The seismic performance of the joint is consistent with that of the cast-in-place reinforced concrete beam-column joint. The hysteretic curve of the joint is full, ductility, and equivalent viscous damping coefficients reach 3.89 and 0.23 , respectively, when slip exists between the connector and the steel beam. The joint demonstrates satisfactory seismic performance. This study provides an experimental basis for the engineering application of the novel prefabricated connection joint.
\end{abstract}

Keywords: Prefabricated connector with ribbed angle steel, Reinforced concrete-steel beam (RCS) exterior joint, Seismic performance, Ductility coefficient

\section{Introduction}

Reinforced concrete column-to-steel beam(RCS) composite frame structure has been widely used in the engineering field in recent years. RCS has become a low-cost and highefficiency structure with advantages of both reinforced concrete and steel members [1]. Compared with pure steel frame structures, reinforced concrete columns can effectively improve not only lateral stiffness and viscous damping but also durability and fire resistance of the structure. Compared with reinforced concrete frame structures, steel beams can enhance the span capability of frame beams [2]. Scholars in the United States and Japan have carried out in-depth studies on this structure since the 1980s [3-5]. The American Society of Civil Engineers (ASCE) formulated ASCE Guidelines in 1994 and revised them in $2004[6,7]$.

Both reinforced concrete columns and steel beams are appropriately designed members in the RCS composite frame structure system. By comparison, beam-column joints are subjected to complex forces, and the performance exerts significant influence on the overall structural performance.

*E-mail address: zaihua_zhang@163.com

ISSN: 1791-2377 @ 2021 School of Science, IHU. All rights reserved. doi:10.25103/jestr.143.11
The performance of RCS joints has become an important part in the study of RCS structural performance. Previous studies showed that the performance of RCS joints varies significantly with beam-column connection structures $[8,9]$. Typical RCS connections include "beam-through" connections in America [10,11] and "column-through" connections in Japan $[12,13]$. Considering that the RCS joints of these two types of connections are evolved from steel reinforced concrete, although the two types of connections have been widely used in practical projects, the joint structures are complex. Moreover, these connections can hardly meet the needs of the current industrial development of construction because of the difficulty in their construction. Although scholars have proposed different joint structural transformation schemes to improve the construction performance of RCS composite joints [1417] and overcome existing drawbacks, such schemes have also brought new defects. Therefore, the effective improvement of the field construction performance of joints has become a key point in the study of the application of RCS composite joints.

Based on the design idea of prefabricated construction, a prefabricated connection structure of RCS composite joint with top and bottom ribbed angle steel was proposed in this study. Moreover, an experimental investigation and analysis 
of the seismic performance of the novel prefabricated connection joints were carried out.

\section{State of the art}

RCS composite joints have been widely investigated. American scholars proposed the concept of RCS composite frame in the 1970s and regarded it as an extension of highrise steel frame. Sheikh [18] and Deierlein [19] carried out an experimental study on the performance of 17 interior joints of RCS frames and obtained two failure modes of beam end and joint domain failures of RCS composite joints. Moreover, a design model of RCS joints was established, and ASCE design guidelines for beam-column flexural connection of composite steel frames were developed on the basis of the experimental study. However, the "Guide" value only allowed the use of RCS composite frames in low- and moderate-intensity areas because the experiment failed to investigate inelastic deformation behavior of joints under reciprocating loads thoroughly. Kanno et al. [20,21] carried out seismic performance tests on 11 interior joints of RCS frames to discuss the applicability of RCS composite joints in high-intensity areas and pointed out that ductility coefficient of properly designed RCS composite joints can reach $3-4$. The shear strength calculation formula given in the "Guide" is conservative. Parra-Montesinos and Weight [22,23] designed and constructed 9 3/4-scale specimens and carried out an experimental study on the performance of exterior joints of the RCS composite frame. The influence of structural measures, such as U-shaped stirrups and steel plates in the joint area, on the seismic performance of exterior joints was investigated, and a new calculation formula for shear capacity was proposed. However, these studies need additional support from experimental data to improve their practicability. The RCS composite frame in Japan is generally regarded as a reformed low-rise RC frame. $\mathrm{RC}$ beams were replaced with steel beams to achieve the purpose of long-span column grid. The performance of beam-column joints with column-through structure was thoroughly investigated. The steel beam and the column were connected in different modes after the steel beam in the beam-column joint area was broken. Architectural Institute of Japan (AIJ) summarized 12 standard types of beamcolumn force transfer structures. Typical connection structures include cover plate, face bearing plate, interior outer diaphragm, and partial SRC beam types [24]. Sakaguchi and Deierlein [18,19] summarized failure modes of cover plate and face bearing plate types and calculation methods of shear capacity by carrying out an experimental study. Hitoshi Morimoto [25] performed an experimental study on the seismic performance of cylindrical steel plate joints with through stiffeners and discussed their influence on the performance of joints. Nishiyama et al. [7] proposed corresponding seismic design guidelines on the basis of existing experimental studies and summarized the design process and basic design formulas of joints for the engineering application of connection joints of cover and face bearing plate types.

The complexity of structures of both beam- and columnthrough joints in the early period increases their difficulty in construction. The connection structure of RCS composite joints based on prefabricated assembly has been widely investigated in recent years with the continuous development of building industrialization. Chinese scholars have carried out many studies in this field [26-29]. Pan et al. [30] established an assembly structure of RCS joints with cantilever beam section. Field steel beam and joints were assembled and connected with bolts by prefabricating joints with cantilever beam section in the factory to realize the assembly of field construction. However, the applied traditional beam-through structure is difficult to construct. Mao [31,32] and Lu [33] carried out experimental studies on the seismic performance of RCS composite joints with weakened end-plate connections at beam ends and RCS composite joints with end-plate connections at steelconcrete composite beams and revealed that prefabricated RCS composite joints based on extended end-plate connection demonstrate satisfactory seismic performance. A large number of bidirectional screws were arranged in the beam-column joint area to realize the assembly construction, but the concrete in the joint area was seriously weakened.

In addition to the end-plate connection, top and bottom angle steel connections are also typical beam-column assembly connection modes. Compared with the end-plate connection, upper and lower angle steel connections show better deformation performance, which is more conducive to the seismic energy dissipation of joints. Assembly connection modes of top and bottom angle steel connections have been comprehensively explored in recent years with indepth studies on the shear performance of ribbed angle steel [34-37]. The assembly connection of ribbed angle steel is mainly used in the beam-column assembly of pure steel frames. However, reports on the RCS joint performance of top and bottom angle steel assemblies are limited. On the basis of performance advantages of the RCS joint and ribbed angle steel connection, a detachable ribbed angle steel beam-column side joint assembly connection structure was designed in this study, whereby high-strength bolts were embedded in the beam-column joint area and steel beams and reinforced concrete columns were firmly connected with high-strength bolts through ribbed angle steel assembly connectors to realize the connection of beam-column exterior joints. Three full-size joints were designed and manufactured for the novel fabricated RCS exterior joints, and the seismic performance test and finite element analysis were carried out. The evaluation results of the influence of the beam-column section size and ribbed assembly angle steel on the seismic performance of the novel fabricated RCS joints can provide a basis for further theoretical analysis of RCS joints with ribbed angle steel.

The remainder of this study is structured as follows. The experiment is introduced in Section 3. The test results of failure mode, hysteretic curve, ductility, and energy dissipation performance of joints are compared and analyzed in Section 4. Finite element simulation and comparative analyses are also conducted in Section 4. Finally, the summary and conclusions are drawn in Section 5.

\section{Methodology}

\subsection{Specimen design and manufacture}

Three RCS hybrid joint specimens were designed, manufactured, and denoted BJD-1, BJD-2, and BJD-3. According to the location of the bending point of the frame structure, the beam member is $1.5 \mathrm{~m}$ long and the column member is $3.3 \mathrm{~m}$ long. Size and relevant parameters of specimens are listed in Table 1 . The basic structure of the joint is shown in Figure 1. The prefabricated concrete column and the H-shaped steel beam are assembled and connected through ribbed angle steel connectors and grade 
10.9 M20 friction high-strength bolts. Assembly bolts of connectors and columns are anchored in the core area of the joint via welding with $90^{\circ}$-bent steel bars. The concrete column is equipped with 4C20 longitudinal reinforcement and C8@100 stirrup. The average cube strength of the concrete in 28 days is $31.7 \mathrm{MPa}$. The material test results of steel beams, connecting angles, and steel bars in columns are presented in Table 2. Pretightening force of high-strength bolts in the beam-column assembly process control is 155 $\mathrm{kN}$.

Table 1. Parameters of specimens

\begin{tabular}{|c|c|c|c|c|c|c|c|c|}
\hline $\begin{array}{c}\text { Specimen } \\
\text { number }\end{array}$ & $\begin{array}{c}\text { Reinforced concrete } \\
\text { column (mm) }\end{array}$ & $\begin{array}{c}\text { Section steel beam } \\
(\mathrm{mm})\end{array}$ & $\begin{array}{c}\text { Size of angle steel } \\
(\mathrm{mm})\end{array}$ & $\mathbf{D}_{\mathrm{b}}(\mathbf{m m})$ & $D_{c}(\mathbf{m m})$ & $\mathbf{T}_{\mathrm{s}}(\mathbf{m m})$ & $\mathbf{m}$ & $\mathbf{n}$ \\
\hline BJD-1 & $250 \times 250$ & HN248×124×5×8 & $120 \times 140 \times 175 \times 12$ & 20 & 20 & 12 & 4 & 0.25 \\
\hline BJD-2 & $300 \times 300$ & $\mathrm{HN} 298 \times 149 \times 5.5 \times 8$ & $120 \times 140 \times 175 \times 12$ & 20 & 20 & 12 & 4 & 0.25 \\
\hline BJD-3 & $350 \times 350$ & HN298 $\times 149 \times 5.5 \times 8$ & $120 \times 140 \times 225 \times 12$ & 20 & 24 & 12 & 6 & 0.25 \\
\hline
\end{tabular}

Note: $\mathrm{Db}$ is the diameter of friction high-strength bolts for reinforced concrete columns; Dc is the diameter of the beam-end friction high-strength bolt; $m$ is the number of high-strength bolts at the beam end; $n$ is the axial compression ratio, $n=N / N u ; N$ is the axial force exerted at the top of the column; $\mathrm{Nu}$ is the theoretical axial compression bearing capacity of the reinforced concrete column; and Ts is the thickness of the angle steel stiffener.
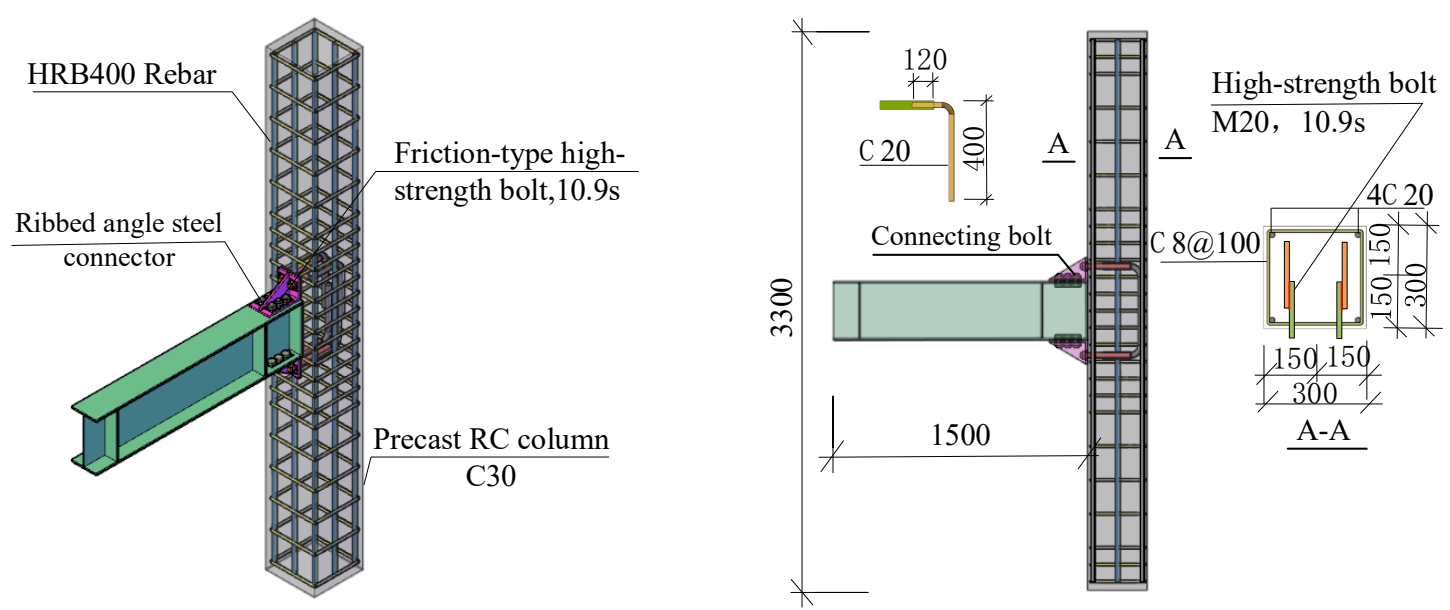

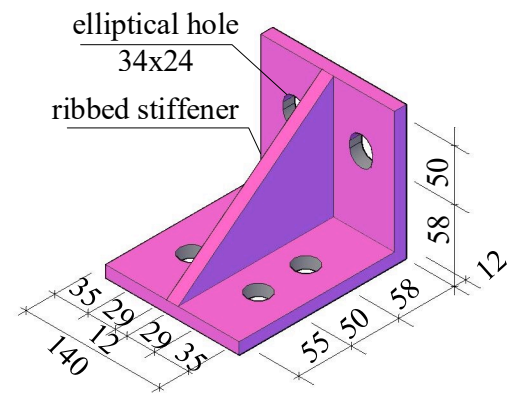

BJD1,2 Assembly connector

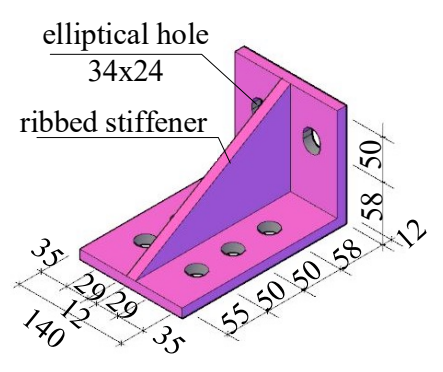

BJD3 Assembly connector

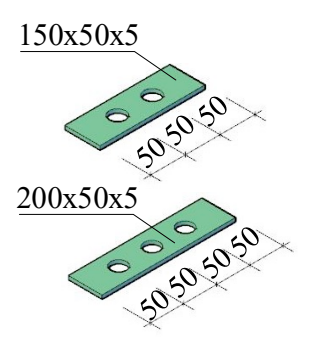

Subplate specification

Fig. 1. Graphical illustration of the particle representation scheme

Table 2. Material properties of steel

\begin{tabular}{c|c|c|c|c}
\hline $\begin{array}{c}\text { Type of } \\
\text { steel }\end{array}$ & $\begin{array}{c}\text { Yield } \\
f_{\mathrm{y}} \\
(\mathbf{M P a})\end{array}$ & $\begin{array}{c}\text { Limit } \\
f_{\mathrm{u}}(\mathbf{M P a})\end{array}$ & $\begin{array}{c}\text { Elasticity } \\
\text { modulus } \\
E_{\mathrm{s}} \mathbf{( M P a )}\end{array}$ & $\begin{array}{c}\text { Elongatio } \\
\mathbf{n}(\%)\end{array}$ \\
\hline $\begin{array}{c}\text { Steel beam } \\
\text { Q235-B }\end{array}$ & 278.1 & 412.8 & $2.01 \times 10^{5}$ & 20.2 \\
$\begin{array}{c}\text { Angle steel } \\
\text { Q345-B } \\
\text { Rebar }\end{array}$ & 416.8 & 557.2 & $1.97 \times 10^{5}$ & 22.7 \\
HRB400 & 421.7 & 581.3 & $1.92 \times 10^{5}$ & 23.1 \\
\hline
\end{tabular}

\subsection{Loading device and system}

The reaction device for hysteretic performance test of exterior joints is shown in Figure 2. Each specimen is subjected to constant axial pressure at the column top and low cyclic load at the beam end. The simplified analysis model is presented in Figure 2(d). According to boundary conditions of the beam and columns, hinge devices are set at the top and bottom of the column to allow the column to rotate in the plane. The bottom hinge is fixed on the rigid floor with high-strength bolts whereas the top hinge is supported on the rigid frame with $\mathrm{H}$-shaped steel beams to restrict the horizontal movement of the column end. The top hinge structure is shown in Figure 2c. A constant axial pressure is first applied to the column top in the test. According to the column axial force of the joint at the actual working state, axial compression ratio of the column is maintained at 0.25 . A low-cycle reciprocating load is applied at the end of the steel beam according to the displacement control. The loading system is shown in Figure 3. 


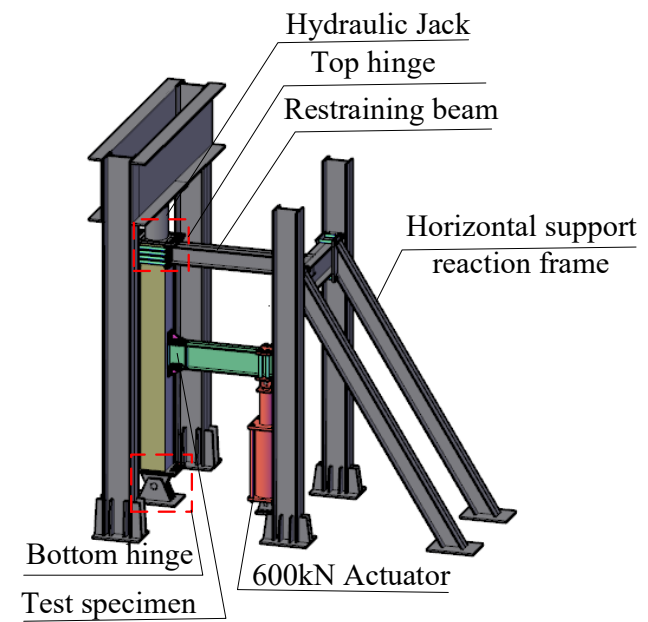

(a) Diagram of the loading device

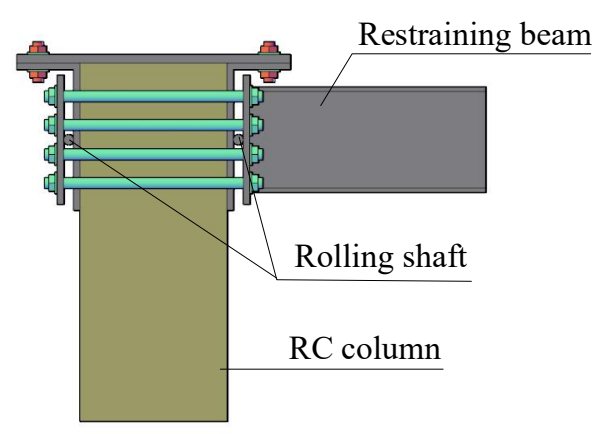

(c) Hinge structure of the column top

Fig. 2. Loading and reaction device

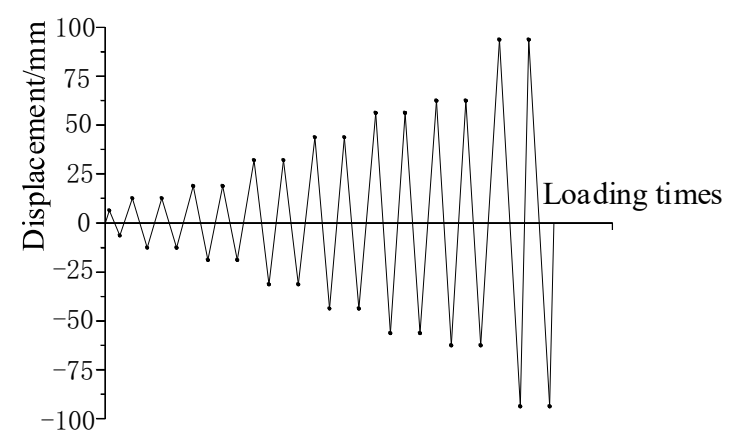

Fig. 3. Loading protocol

\subsection{Layout and measurement contents of measuring points}

Fig. 4 presents the layout of displacement measuring points of the specimen. Horizontal displacement transducers D1 and D2 are arranged on the side of the column in the core area of the specimen. $\mathrm{u} 1$ and $\mathrm{u} 2$ represent the deformation of core areas of beam-column joints. Vertical transducers D3 and D4 are located at the beam end, and the measured $\mathrm{u} 3$ and $\mathrm{u} 4$ can represent the rotation angle of the node beam end. Dial gauges D5 and D6 are placed at upper and lower ends of the column, and the measured $\mathrm{u} 5$ and $\mathrm{u} 6$ represent the rigid body rotation of the device. The angle of joints can be obtained according to $\mathrm{u} 1, \mathrm{u} 2, \mathrm{u} 3$, and $\mathrm{u} 4$. Figure 5 reveals the relative angular deformation of beams and columns.

$\theta_{r}=\theta_{\mathrm{r}}^{\mathrm{b}}-\theta_{\mathrm{r}}^{\mathrm{c}}=\frac{u_{4}-u_{3}}{h_{b f}}-\frac{u_{1}-u_{2}}{h_{c f}}$

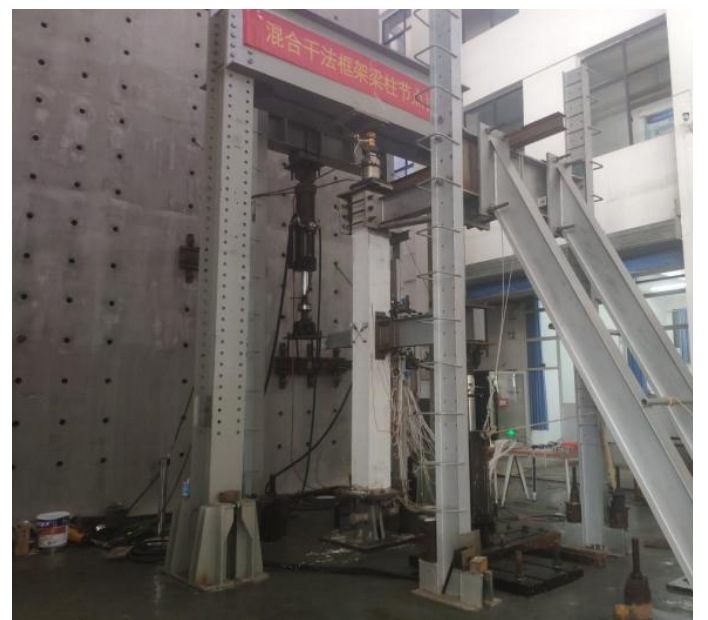

(b) Loading device

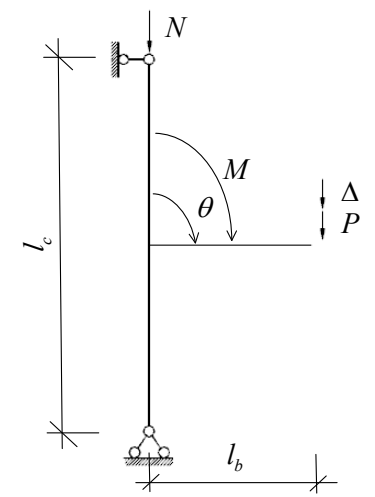

(d) Diagram of the node calculation

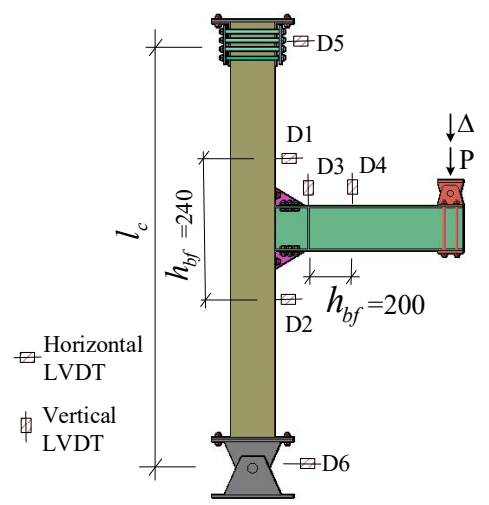

Fig. 4. Layout of displacement transducers

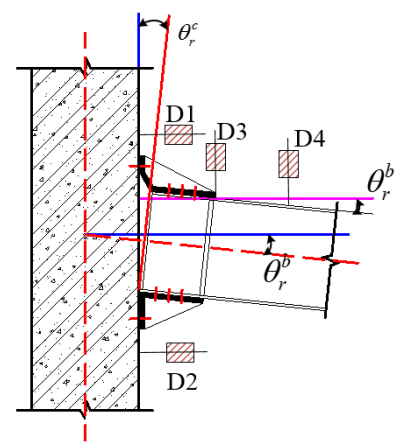

Fig. 5. Diagram of the relative rotation of the beam-column

\section{Result Analysis and Discussion}

4.1 Test Phenomena and Failure Mode

The load at the beam end during the loading process is 20.8 $\mathrm{KN}$ when the displacement of specimen BJD-1 is loaded to 6 
$\mathrm{mm}$. The first crack appears near the height of the bolt at the column end in the short leg of the connecting angle steel at the lower end of the beam. The load at the beam end is 59.4 $\mathrm{KN}$ and the first cross-inclined crack is formed in the core area of the column when the load is $-30 \mathrm{~mm}$ in the sixth lap. The load at the end of the beam suddenly decreases from $69 \mathrm{KN}$ to $65.1 \mathrm{KN}$ and the slip between the angle steel and the steel beam can be observed when the load is $42 \mathrm{~mm}$ in the eighth lap. The load at the end of the beam gradually increases and the oblique crack of the column extends and widens with the increase of displacement. The load at the end of the beam is $-71.4 \mathrm{KN}$ and a crack appears every 100 $\mathrm{mm}$ from the height of the high-strength bolt at the bottom angle when the displacement is loaded to $-90 \mathrm{~mm}$ in the fourteenth lap. High-strength bolts at upper and lower ends of the column demonstrate numerous cracks, and many inclined cracks appear in the core area of joints. The maximum crack width reaches $5 \mathrm{~mm}$, the concrete column is destroyed, and members stop loading. Failure modes of specimens are shown in Figures 6(a) - 6(c).

The column section of specimen BJD-2 is larger than those of BJD-1 with the same angle steel connectors. The beam end load is $44.9 \mathrm{KN}$ and the first crack appears near the height of the column end bolt in the short leg of the connecting angle steel at the lower end of the beam when the displacement is loaded to $12 \mathrm{~mm}$ in the second circle. The load at the beam end suddenly decreases from $79 \mathrm{KN}$ to 69.1 $\mathrm{KN}$ and the slip occurs between the angle steel and the steel beam when the load is $30 \mathrm{~mm}$ in the sixth lap. The slip between the connector and the steel beam also increases but the load at the beam end only changes slightly as the applied displacement increases further. The load at the beam end shows a decreasing trend and the stiffening rib of the top angle steel yields under pressure when the load is $42 \mathrm{~mm}$ in the eighth lap. The crack change of the column is unclear in the process. The load at the beam end decreases to -54.1 $\mathrm{KN}$, which is below $85 \%$ of the peak load, and the loading is

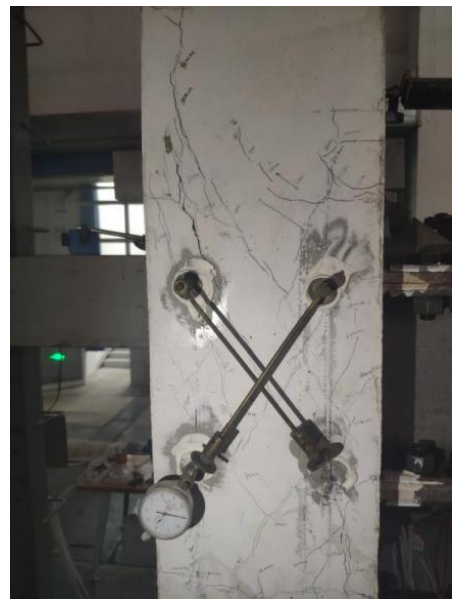

(a) Failure of concrete in the core area of BJD-1

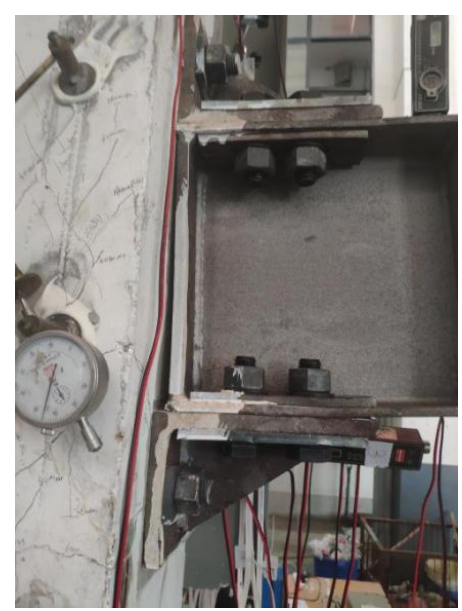

(b) Sliding failure at the beam end of BJD-1

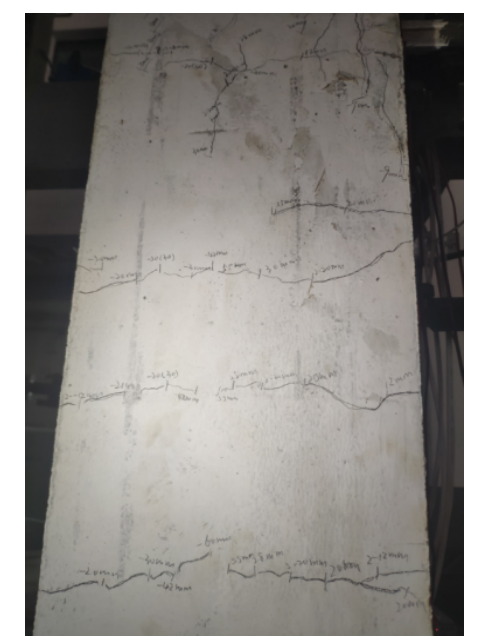

(c) Concrete cracking of BJD-1 steel beam against the side column stopped when the displacement is loaded to $-55 \mathrm{~mm}$ in the eleventh lap. Failure modes of specimens are shown in Figures $6(d)-6(f)$. The slip of the steel beam end of the joint is large, but the concrete crack in the core area is unclear.

Beam-column sections of specimens BJD-3 and BJD-2 are the same, but angle steel connectors of BJD-3 are larger than those of BJD-2. Three rows of high-strength bolts are used to connect with steel beams. The early stress deformation of BJD-3 is basically the same as that of BJD-2. The load at the beam end is $46.4 \mathrm{kN}$ and the first crack appears at the short leg of the angle steel near the height of the bolt at the column end when the load is $12 \mathrm{~mm}$ in the second lap. The load at the beam end gradually increases with the increase of applied displacement. The load at the beam end is $87.7 \mathrm{KN}$, the bottom angle steel stiffener yields in tension, and the top angle steel stiffener yields in compression when the load is $30 \mathrm{~mm}$ in the sixth lap. Slip is absent between the angle steel connector and the steel beam but the column concrete in the core area of the joint produces evident shear failure during the entire loading process. The peak load at the beam end is $108.7 \mathrm{KN}$ when the displacement is loaded to $55 \mathrm{~mm}$ in the tenth lap. The load at both ends decreased to $-85.6 \mathrm{KN}$ and the test ends after loading to $-70 \mathrm{~mm}$ in the twelfth lap. Failure modes of BJD-3 are shown in Figures 6(g) - 6(j).

The analysis of this phenomena showed that the RSC exterior joint with ribbed angle steel is an assembled RCS joint that can adapt to industrial production. The RSC exterior joint presents the following failure modes: (1) sliding failure of the high-strength bolt connection between the connector and the steel beam and (2) column concrete failure in the core area of the joint. Table 3 summarizes the main failure modes of each specimen. 


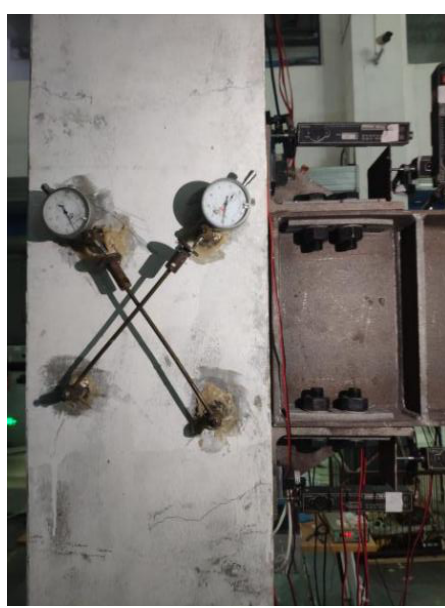

(d) Failure of concrete in the core area of

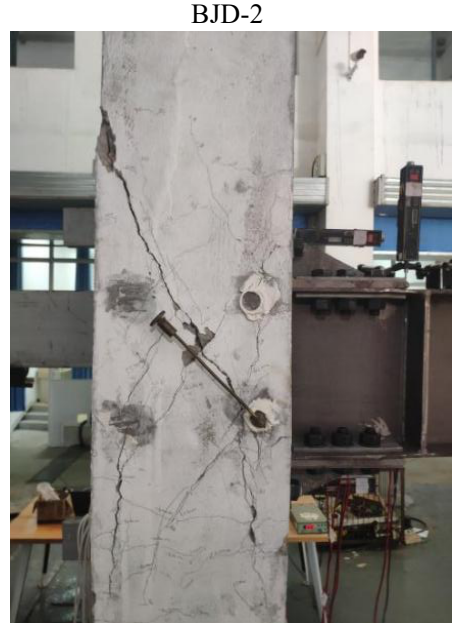

(g) Failure of concrete in the core area of BJD-3

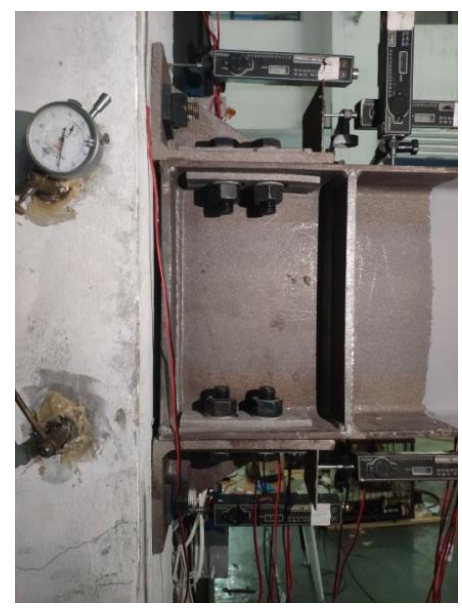

(e) Sliding failure at the beam end of BJD-2

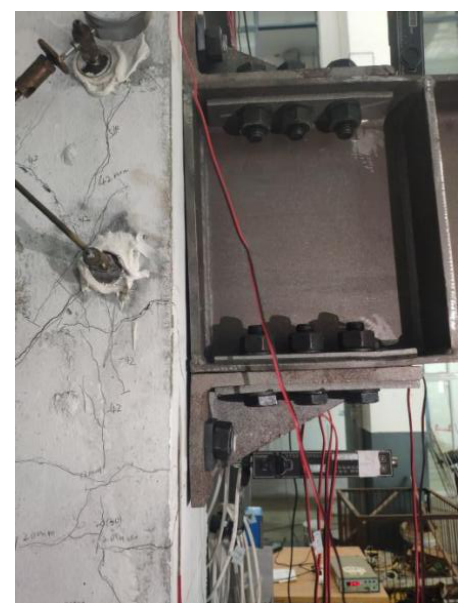

(h) Absence of slip at the beam end of BJD-3

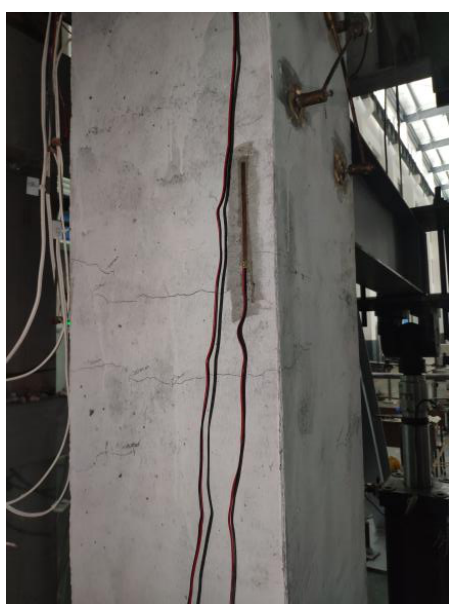

(f) Concrete cracking of BJD-2 steel beam against the side column

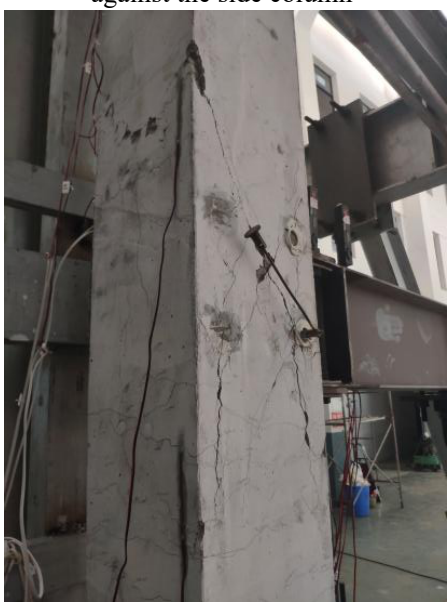

(i) Concrete cracking of BJD-3 steel beam against the side column

Fig. 6. Typical failure modes of specimens

Table 3. Failure mode of specimens

\begin{tabular}{c|c}
\hline $\begin{array}{c}\text { Specimen } \\
\text { s }\end{array}$ & Main failure modes \\
\hline BJD-1 & $\begin{array}{c}\text { Cracking of the column concrete in the core area and } \\
\text { slip appears between the connector and the steel beam }\end{array}$ \\
BJD-2 & Slip appears between the connector and the steel beam \\
BJD-3 & Cracking of the column concrete in the core area \\
\hline
\end{tabular}

\subsection{Hysteretic curve}

Beam end load-displacement curves of the three specimens are illustrated according to test record data, as shown in figure 7. Hysteretic curves of specimens BJD-1 and BJD-2 are basically reverse S-shaped and full, while the hysteretic

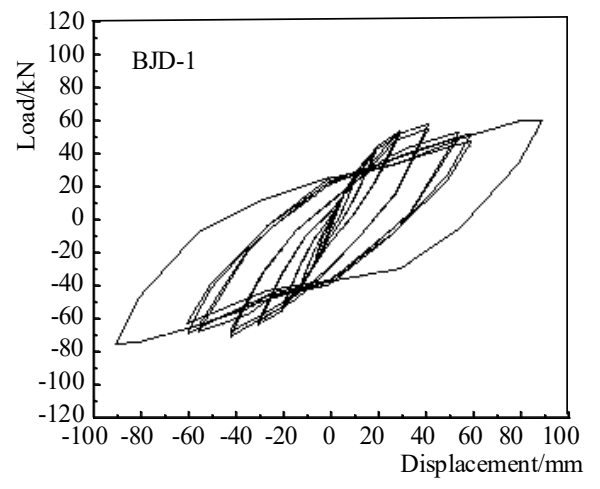

(a) BJD-1 hysteretic curve curve of specimen BJD-3 is bow-shaped with pinch phenomenon. The comparison of hysteretic curves in figure 7(d) showed that BJD-1 presents the failure mode of slip and concrete failure in the core area, with the fullest hysteretic curve and the strongest plastic deformation ability. BJD-2 mainly produces slip failure, and its ultimate deformation is smaller than those of BJD-1 and BJD-3. On the basis of BJD-2, the size of the connecting angle steel and column sections of BJD-3 increase and the ultimate bearing capacity of joints significantly improves. Although the pinch phenomenon exists in the hysteretic curve, the overall energy consumption is significantly larger than that of BJD2.

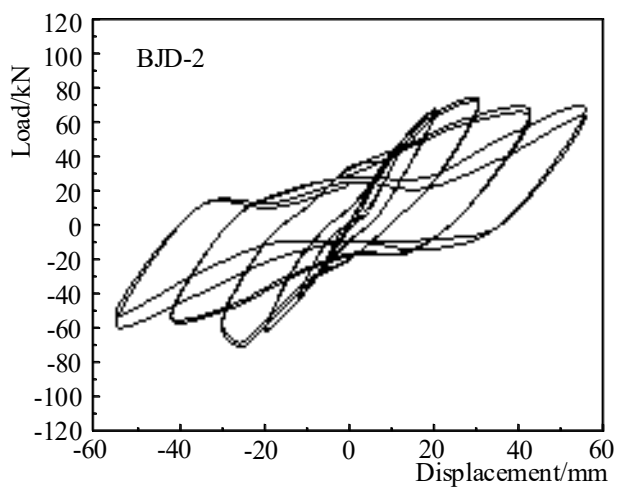

(b) BJD-2 hysteretic curve 


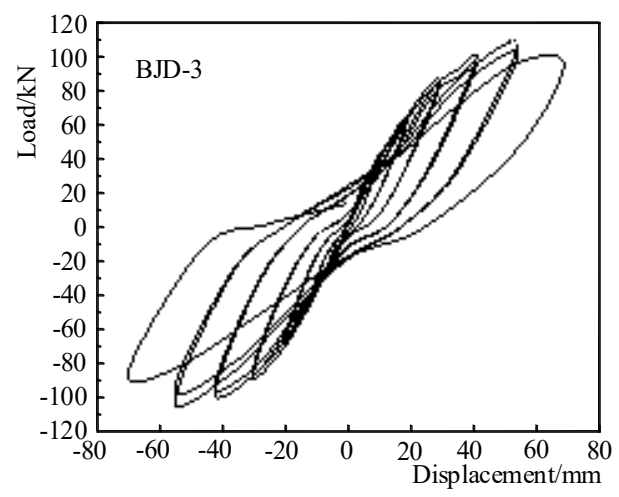

(c) BJD-3 hysteretic curve

Fig. 7. Hysteretic curve of specimens

\subsection{Skeleton curve}

Figure 8 shows the beam end load-displacement curves of the three specimens. Table 4 summarizes the cracking load, yield load, slip load, and beam end displacement of each specimen. The S-shaped skeleton curves of the three specimens indicated that three processes occur under low cyclic loading, namely, elastic stage, plastic stage, and ultimate failure. The load displacement in the initial loading stage shows an evident linear relationship. Rising sections of curves in the elastic stage basically coincide. However, the bearing capacity of joints in the elastic-plastic stage is significantly different. Enlargement of the beam-column section fails to enhance the bearing capacity of the joint effectively (the beam-column section of BJD-2 is larger than that of BJD-1, but yield load values are nearly the same), but the initial rotational stiffness of the joint can be increased to some extent for the same assembly connection angle steel. The ultimate bending capacity of joints increases significantly for the same beam-column section due to additional high-strength bolts between angle steel and steel beams (i.e., increasing the antisliding capacity between connectors and steel beams). Assembly connectors of BJD-3

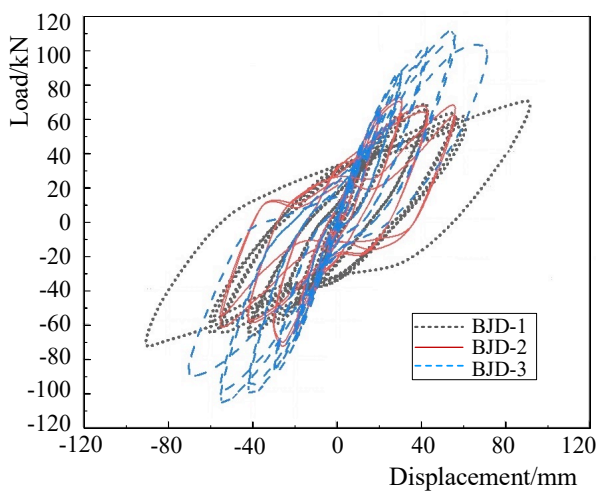

(d) Comparison of hysteretic curves of the three specimens

increase from two rows of assembly bolts of specimen BJD2 to three rows of assembly bolts, and the ultimate bending capacity of joints increases by $59.7 \%$ on average.

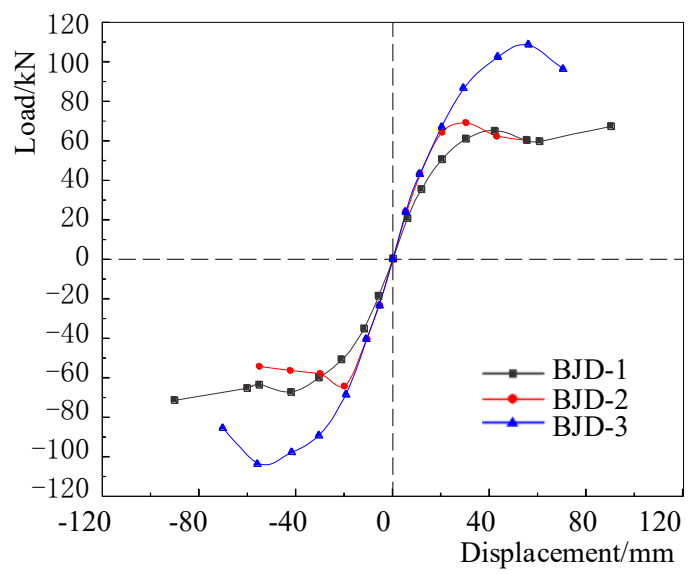

Fig. 8. Skeleton curves of exterior joints

Table 4. cyclic loading test results

\begin{tabular}{|c|c|c|c|c|c|c|c|c|}
\hline \multirow{2}{*}{ Specimen number } & \multicolumn{2}{|c|}{ Crack } & \multicolumn{2}{|c|}{ Slip } & \multicolumn{2}{|c|}{$\begin{array}{l}\text { Yield value } \\
\end{array}$} & \multicolumn{2}{|c|}{ Limit value } \\
\hline & $\Delta(\mathbf{m m})$ & $\mathbf{P}(k N)$ & $\Delta(\mathbf{m m})$ & $\mathbf{P}(k N)$ & $\Delta(\mathbf{m m})$ & $\mathbf{P}(k N)$ & $\Delta(\mathbf{m m})$ & $\mathbf{P}(k N)$ \\
\hline BJD-1 & $\begin{array}{c}6 \\
-6\end{array}$ & $\begin{array}{c}20.8 \\
-24.2\end{array}$ & $\begin{array}{c}42 \\
-42\end{array}$ & $\begin{array}{c}65 \\
-67\end{array}$ & $\begin{array}{c}26.6 \\
-31.4\end{array}$ & $\begin{array}{c}57.4 \\
-60.3\end{array}$ & $\begin{array}{c}90 \\
-90\end{array}$ & $\begin{array}{c}67.5 \\
-71.4\end{array}$ \\
\hline BJD-2 & $\begin{array}{c}12 \\
-12 \\
\end{array}$ & $\begin{array}{l}44.9 \\
-44 \\
\end{array}$ & $\begin{array}{c}26 \\
-26 \\
\end{array}$ & $\begin{array}{c}79 \\
-80 \\
\end{array}$ & $\begin{array}{c}20.5 \\
-18.9 \\
\end{array}$ & $\begin{array}{c}64.3 \\
-61.2 \\
\end{array}$ & $\begin{array}{c}55 \\
-55 \\
\end{array}$ & $\begin{array}{c}60.1 \\
-54.1 \\
\end{array}$ \\
\hline BJD-3 & $\begin{array}{c}12 \\
-12\end{array}$ & $\begin{array}{c}46.4 \\
-45.1\end{array}$ & $\begin{array}{l}1 \\
1\end{array}$ & $\begin{array}{l}1 \\
1\end{array}$ & $\begin{array}{c}35 \\
-33\end{array}$ & $\begin{array}{c}93.3 \\
-90.7\end{array}$ & $\begin{array}{c}70 \\
-70\end{array}$ & $\begin{array}{c}96.8 \\
-85.6\end{array}$ \\
\hline
\end{tabular}

\subsection{Ductility and Energy Consumption Performance of} Joints

The ductility ratio of the joint is the ratio of the limit nodal rotation angle to the yield rotation angle, $\mu=\theta_{u} / \theta_{y}$. The nodal angle is determined according to Formula (1). Table 5 summarizes the characteristic rotation angle and ductility coefficient of each specimen. Ductility factors of specimens (BJD-1 and BJD-2) with slip between connectors and steel beams reach $3.7-3.89$, which is consistent with the ductility performance of concrete-filled steel tube beam-column joints with diaphragm penetration in [38]. The ductility of joints for specimens with two failure modes is greater, and the ductility coefficient of specimen BJD-1 is higher than that of specimen BJD-2 by $5.2 \%$. The corner ductility of the joint evidently decreases when only concrete failure occurs in the core area of the joint. The ductility coefficient of specimen BJD-3 is slightly higher than the required cast-inplace concrete member ductility coefficient of 2.0 and $45.3 \%$ lower than that of specimen BJD-2. The test results showed that reasonable matching of sections of beams, columns, and angle steel connectors helps control failure modes of joints and significantly improves the ductility of joints of prefabricated RCS with angle steel.

Table 5. Rotation angle ductility ratio

\begin{tabular}{|c|c|c|c|c|c|c|}
\hline \multirow{2}{*}{$\begin{array}{c}\text { Specimen } \\
\text { number }\end{array}$} & \multirow{2}{*}{ Direction } & Yield angle & Peak rotation angle & Ultimate rotation angle & \multirow{2}{*}{$\begin{array}{l}\text { Ductility } \\
\text { ratio }(\mu)\end{array}$} & \multirow{2}{*}{ Average } \\
\hline & & $\theta_{y}\left(10^{-2} \mathrm{rad}\right)$ & $\theta_{\max }\left(10^{-2} \mathbf{r a d}\right)$ & $\theta_{u}\left(10^{-2}\right.$ rad $)$ & & \\
\hline BJD-1 & Forward direction & 0.014 & 0.057 & 0.057 & 4.071 & 3.893 \\
\hline
\end{tabular}




\begin{tabular}{c|c|c|c|c|c}
\hline & Reverse direction & -0.014 & -0.052 & -0.052 & 3.714 \\
\hline \multirow{2}{*}{ BJD-2 } & Forward direction & 0.011 & 0.021 & 0.039 & 3.515 \\
\cline { 2 - 5 } & Reverse direction & -0.009 & -0.011 & -0.035 & 3.889 \\
\hline \multirow{2}{*}{ BJD-3 } & Forward direction & 0.019 & 0.026 & 0.039 & 2.052 \\
\cline { 2 - 6 } & Reverse direction & -0.018 & -0.031 & -0.036 & 2.026 \\
\hline
\end{tabular}

The area surrounded by the hysteretic curve reflects the energy consumed from loading to structural failure. The equivalent viscous damping coefficient $h_{e}$ and energy dissipation coefficient $E$ are used to evaluate the energy dissipation capacity of members. The two indexes are expressed as follows:

$E=\frac{1}{2 \pi} \times \frac{S_{(A B C+C D A)}}{S_{(O B E+O D F)}}$,

$E=2 \pi h_{e}$,

where $S_{(A B C++C D A)}$ is the area of hysteresis loop that reflects the energy consumed in one cycle of the hysteresis loop and $S_{(O B E+O D F)}$ is the area enclosed by triangles OBE and ODF, as shown in Figure 9.

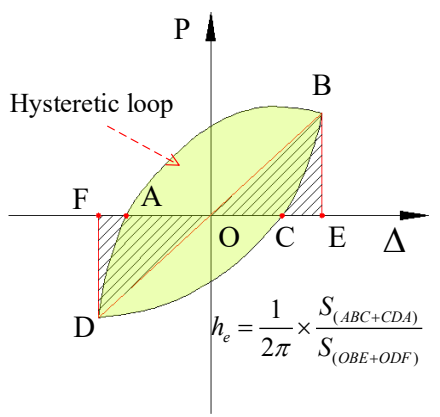

Fig. 9. Diagram for the calculation of the equivalent viscous damping coefficient

Table 6 presents the index values of energy dissipation capacity of the three specimens on the basis of the above method. The equivalent viscous damping coefficient of reinforced concrete beam-column joints is approximately 0.1 [39]. However, the energy dissipation performance of joints BJD- 1 and BJD-2 is evidently better than that of reinforced concrete joints because the slip between connectors and steel beams under the ultimate stress state reaches 0.24 in this study. However, the energy dissipation performance of BJD3 with shear failure in the core area is basically consistent with that of reinforced concrete joints.

Table 6. Equivalent viscous damping and energy dissipating factors

\begin{tabular}{c|c|c}
\hline Specimen number & $h_{e}$ & $E$ \\
\hline BJD-1 & 0.23 & 1.47 \\
BJD-2 & 0.24 & 1.48 \\
BJD-3 & 0.11 & 0.67 \\
\hline
\end{tabular}

\subsection{Numerical simulation analysis}

\subsubsection{Material model}

ABAQUS finite element analysis software is used to analyze the stress of joints of RSC column-H-shaped steel beam assembled with ribbed angle steel. The concrete constitution is determined according to the uniaxial stress-strain constitutive relation curve of concrete in Code for Design of Concrete Structures (GB5001-2010) considering the plastic damage of concrete during loading. The ideal elastic-plastic model is adopted. The connection of steel beam and angle steel is simplified in a threefold line model with yield platform, and a double-fold line model is used for the highstrength bolt. The material constitutive model is shown in Figure 10.

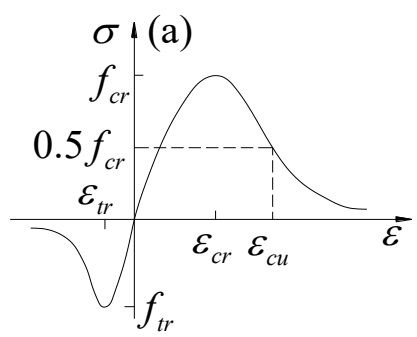

(a) Constitutive model of concrete

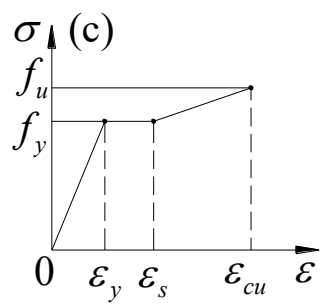

(c) Constitutive model of steel beam and angle steel

Fig. 10. Finite element analytical model

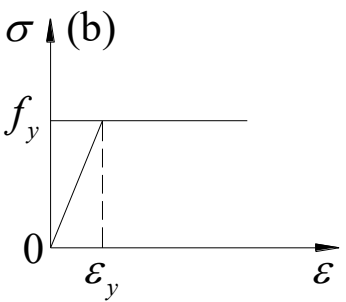

(b) Constitutive model of column reinforcement

$\sigma_{\mathrm{l}}(\mathrm{d})$

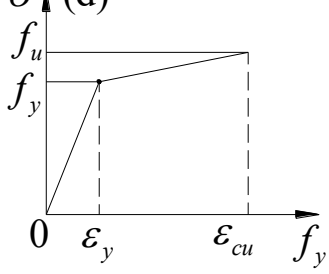
high-strength bolt (d) Constitutive model of

\subsubsection{Construction of the finite element model}

The assembled reinforced concrete column, steel beam, angle steel connector, and high-strength bolt are simulated via eight-node reduction integral element C3D8R. Truss element T3D2 is used for longitudinal reinforcement and stirrup in the concrete column. These elements are embedded into the concrete column through the Embedded command without considering bond slip. The 3D solid element C3D8R is applied to establish the model and simulate the stress of embedded steel bars accurately, and the sliding between steel beams and angle steel connectors, prefabricated reinforced concrete columns, and angle steel connectors are accurately simulated by reasonably setting contact attributes. The contact attribute in this study is surface-to-surface contact, and normal and tangential contacts are considered. Hard contact is used in the normal direction, and Coulomb friction is used in the tangential direction. The friction coefficient is 0.3 .

Both calculation accuracy and time should be considered in grid division. The model is divided through structured grid division and grids in the core area and other parts with complex stress are encrypted after cutting and subdividing. The grid division of the node specimen is shown in Figure 11 .

The joint numerical simulation model and its boundary conditions are established according to real boundary conditions of the test and the specimen model. Boundary conditions and loading modes of the model are presented in Figure 12. Three reference points are set at upper and lower ends of the column and near the beam end to couple with their loading surfaces. Boundary conditions and loads are applied to corresponding reference points. Bottom ends of 
finite element model columns are set as fixed bearings, which can only rotate around the X-axis. Releasing U3 and UR1 degrees of freedom of the reference point is necessary to apply the axial force at the column top and limit the lateral displacement and lateral rotation of the prefabricated concrete column. The bearing form is sliding hinge bearing and $\mathrm{U} 1=\mathrm{U} 2=\mathrm{UR} 2=\mathrm{UR} 3=0$. Three degrees of freedom $(\mathrm{U} 2$, U3, and UR1) of the reference point are released for both ends of the steel beam to apply vertical displacement load, where $\mathrm{U} 1=\mathrm{UR} 2=\mathrm{UR} 3=0$.
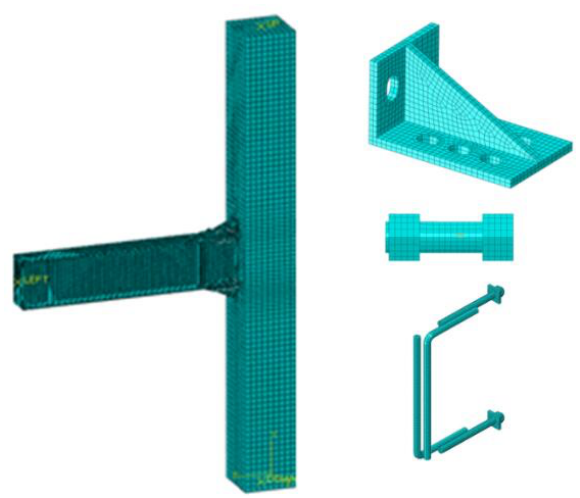

Fig. 11. ABAQUS model grid element

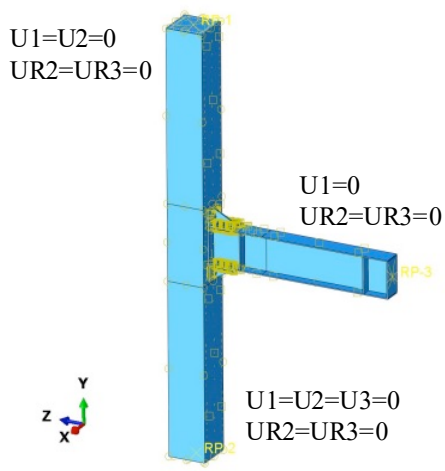

Fig. 12. Boundary conditions of the specimen model

\subsubsection{Stress distribution and failure characteristics}

The stress at the beam end of the joint and the damage of concrete in the core area can be investigated using the above analysis model. Figure 13 shows the beam end stress nephogram of each specimen under the limit load condition, including the stress condition of angle steel connectors and $\mathrm{H}$-shaped steel beams. The stress of the three specimens at stiffening ribs of angle steel connectors and connecting holes of high-strength bolts connected with columns is the maximum. However, BJD-1 and BJD-2 present the largest and smallest cross-section range of yielding, respectively. The beam - column section of BJD-1 is smaller than that of specimen BJD-2, but their yield loads are similar. The comparison of stress nephograms in Figures 13(a) and 13(b) showed that the cross-section performance of BJD-1 is more fully exerted than that of BJD-2. The comparison of Figures 13(b) and 13(c) illustrated that the yield section of BJD-3 steel beam is significantly larger than that of BJD-2 and the yield load of the joint also evidently increases under the condition of the same beam - column section. Meanwhile, the stress nephogram showed that slip occurs between angle steel connectors and steel beams of BJD-1 and BJD-2 but evident slip is absent between connectors and steel beams of BJD-3 under the limit load condition. This finding is consistent with the experimental phenomenon.

Figure 14 shows the tensile damage nephogram of the core concrete of the concrete column. The damage value (DAMAGE C and T) of concrete is close to 0.9, and the concrete is crushed or cracked. Maximum damage values of BJD- 1 and BJD-3 in the joint area are close to 0.9 under the action of external force, thereby indicating that the concrete in the joint area is seriously damaged but the damage value of only a few areas of BJD-2 is close to 0.9 without serious damage in most areas. This finding is consistent with the experimental damage phenomenon. Hence, the analysis results of the finite element model are clearly reasonable.

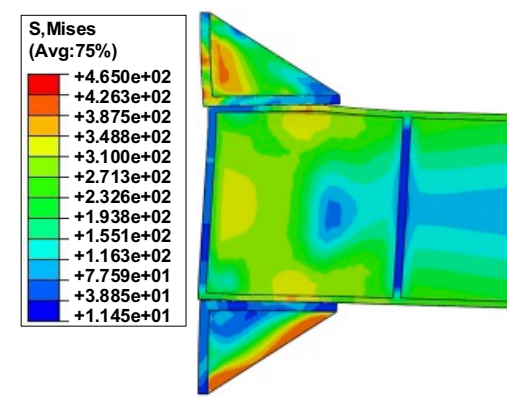

(a) BJD-1

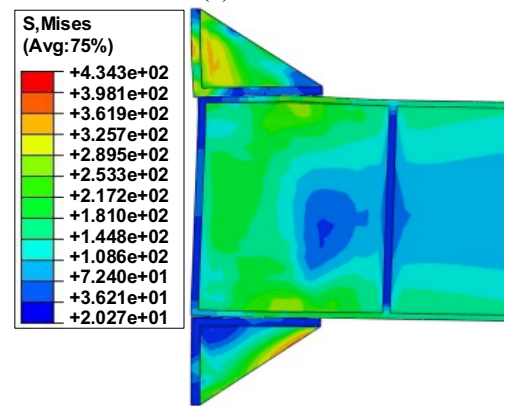

(b) BJD-2

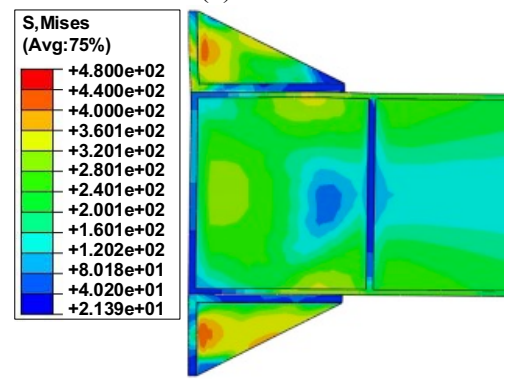

(c) BJD-3

Fig. 13. Von Mises stress nephogram of each beam end specimen 


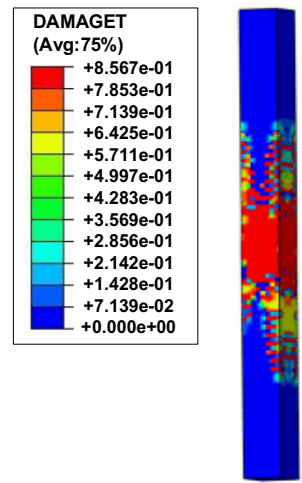

(a) BJD-1

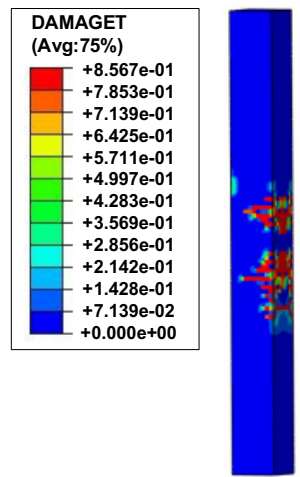

(b) BJD-2

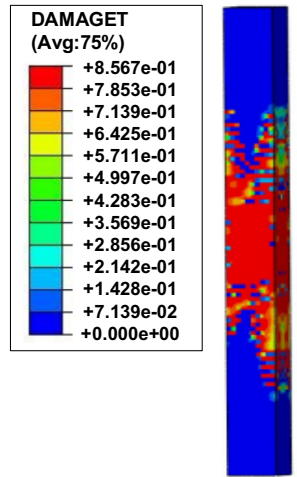

(c) BJD-3

Fig. 14. Damage distribution of the RC column of each specimen

\subsubsection{Comparison of skeleton curves}

Figure 15 presents the comparison of load - displacement skeleton curves calculated by finite element method and skeleton curves measured by experiments under low cyclic loading. The displacement and load at the beam end when joints enter the yield and load limit are listed in Table 7. The comparison of skeleton curves in Figure 15 showed that the finite element analysis structure is basically consistent with the test results in the elastic stage but a certain deviation exists in the elastic-plastic stage. Data in Table 4 showed that the finite element analysis results of joint yield displacement are smaller than the measured results and the corresponding yield load is also smaller. A displacement meter is not installed at the beam end, and the beam end displacement is the output value of the beam end displacement read by the servo system that includes the elastic deformation of the connecting end plate between the actuator and the steel beam. Consequently, the analyzed yield displacement is smaller than the measured displacement. The overall deviation demonstrated that maximum deviations of yield and ultimate loads are 14.3\% and $21.7 \%$, respectively. The calculated results are basically consistent with the test results. Hence, the proposed finite element analysis model can better reflect the actual performance of joints.

Table 7. Comparison between the finite element calculation and test results

\begin{tabular}{|c|c|c|c|c|c|c|c|c|c|c|}
\hline \multirow{3}{*}{$\begin{array}{l}\text { Specimen } \\
\text { number }\end{array}$} & \multicolumn{5}{|c|}{ Yield value } & \multicolumn{5}{|c|}{ Limit value } \\
\hline & \multicolumn{2}{|c|}{ Test } & \multicolumn{2}{|c|}{ Finite element } & \multirow{2}{*}{$\begin{array}{c}\begin{array}{c}\text { Load } \\
\text { deviation }\end{array} \\
\left|\mathrm{P}^{\prime}-\mathrm{P}\right| / \mathrm{P}\end{array}$} & \multicolumn{2}{|c|}{ Test } & \multicolumn{2}{|c|}{ Finite element } & \multirow{2}{*}{$\begin{array}{c}\begin{array}{c}\text { Load } \\
\text { deviation }\end{array} \\
\left|\mathrm{P}^{\prime}-\mathrm{P}\right| / \mathrm{P}\end{array}$} \\
\hline & $\Delta(\mathbf{m m})$ & $\mathbf{P}(k N)$ & $\Delta(\mathbf{m m})$ & $\mathbf{P}^{\prime}(k N)$ & & $\Delta(\mathbf{m m})$ & $\mathbf{P}(k N)$ & $\Delta(\mathbf{m m})$ & $\mathbf{P}^{\prime}(k N)$ & \\
\hline BJD-1 & $\begin{array}{c}26.6 \\
-31.4\end{array}$ & $\begin{array}{c}57.4 \\
-60.3\end{array}$ & $\begin{array}{c}25.32 \\
-24.85\end{array}$ & $\begin{array}{c}50.6 \\
-51.7\end{array}$ & $\begin{array}{l}11.8 \\
14.3\end{array}$ & $\begin{array}{c}90 \\
-90\end{array}$ & $\begin{array}{c}67.5 \\
-71.4\end{array}$ & $\begin{array}{c}90 \\
-90\end{array}$ & $\begin{array}{c}71.5 \\
-75.4\end{array}$ & $\begin{array}{l}5.9 \\
5.6\end{array}$ \\
\hline BJD-2 & $\begin{array}{c}20.5 \\
-18.9\end{array}$ & $\begin{array}{c}64.3 \\
-61.2\end{array}$ & $\begin{array}{r}17.74 \\
-17.9\end{array}$ & $\begin{array}{c}57.6 \\
-57.2\end{array}$ & $\begin{array}{c}10.4 \\
6.5\end{array}$ & $\begin{array}{c}55 \\
-55\end{array}$ & $\begin{array}{c}60.1 \\
-54.1\end{array}$ & $\begin{array}{c}55 \\
-55\end{array}$ & $\begin{array}{c}62.8 \\
-59.2\end{array}$ & $\begin{array}{l}4.5 \\
9.4\end{array}$ \\
\hline \multirow[b]{2}{*}{ BJD-3 } & 35 & 93.3 & 27.85 & 87.3 & 6.4 & 70 & 96.8 & 70 & 102.6 & 5.9 \\
\hline & -33 & -90.7 & -27.27 & -91.2 & 5.3 & -70 & $\begin{array}{c}-8 \\
.6\end{array}$ & -70 & -104.2 & 21.7 \\
\hline
\end{tabular}

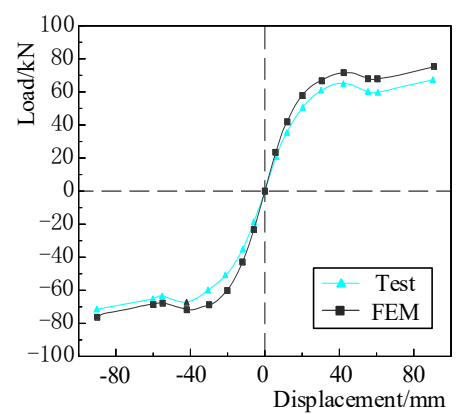

(a) BJD-1

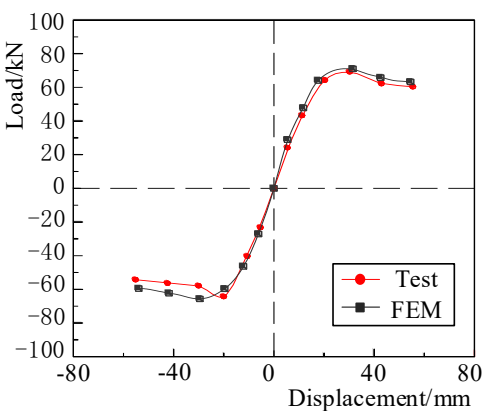

(b) BJD-2

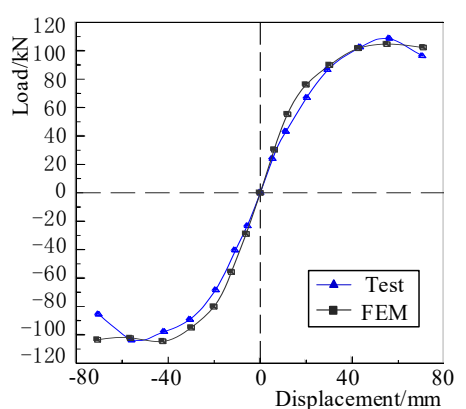

(c) BJD-3

Fig. 15. Cyclic load versus displacement skeleton curve

\section{Conclusions}

An RCS composite frame exterior joint with ribbed angle steel was proposed to improve the construction performance of prefabricated RCS joints, and an experimental investigation and finite element analysis were carried out on its seismic performance. Moreover, the failure mode, hysteretic performance, ductility, and energy dissipation performance of the novel prefabricated RCS joint were discussed and analyzed. The following conclusions can be drawn from this study:
(1) Failure modes of joints can be expressed in the following forms according to the difference of resistance matching among reinforced concrete columns, H-shaped steel beams, and ribbed angle steel connectors: (a) slip failure between connectors and steel beams, (b) shear failure of concrete in the core area of beam-column connections, and (c) failure mode of situations (a) and (b).

(2) The hysteretic curve of the joint is evidently pinched and the ductility and energy dissipation performance are similar to those of the cast-in-place reinforced concrete joint when only shear failure exists in the core area. The 
hysteretic curve of the joint is inverse S-shaped and the seismic performance is satisfactory when slip failure occurs between the assembly connector and the steel beam. The ductility is basically consistent with that of the concretefilled steel tube beam-column joint with diaphragm through.

(3) The bending bearing capacity of the joint with sliding failure between the fitting and the steel beam is controlled by the antisliding bearing capacity of high-strength bolts between fittings and steel beams. The enlargement of cross sections of the beam and the column fails to improve the bending bearing capacity of joints effectively in this case. However, enhancing the antisliding bearing capacity of the high-strength bolt between the assembly connector and the steel beam under the condition of the same beam-column section can effectively improve the bending bearing capacity of the joint.

(4) The failure mode, skeleton curve, and bearing capacity of specimens obtained from finite element analysis are basically consistent with the test results. Element types, material constitutive relations, and failure criteria adopted in the finite element analysis model are feasible and reasonable and can be used to explore the mechanical performance of RCS joints with ribbed angle steel further. The analysis results can provide a basis for developing a new seismic design method of prefabricated RCS joints.
On the basis of the experimental investigation and finite element analysis, the reliability of the novel prefabricated RCS composite joint with top and bottom ribbed angle steel was proven in this study. The simple structure improves the convenience in assembly construction and promotes its practical application in fabricated structural engineering. The test results can provide a reference for the promotion and application of the novel fabricated RCS composite joint. Considering the limited number of joint parameters investigated in the experiment, a follow-up investigation can further discuss the influence of joint parameters on the joint performance based on the proposed finite element model as well as summarize, analyze, and develop the seismic design method of joints.

\section{Acknowledgements}

This work was supported by the Hunan Natural Science Foundation (2018JJ2020 and 2020JJ5018) and the Scientific Research Project of Education Department of Hunan Province (19A095 and 19B099).

This is an Open Access article distributed under the terms of the Creative Commons Attribution License.

\section{References}

1. Men J J, Shi Q X, Zhou Q. "Overview of the Research on Connections in Composite Frames Consisting of Reinforced Concrete Column and Steel Beam". Advanced Materials Research, 368, 2012, pp.568-572.

2. Lan, Q.Y., "Research on Seismic Performance of Assembled Bolt Connection Reinforced Concrete Column-steel Beam Composite Frame Joints". Master thesis of Nan Chang University, China, 2020, pp.1-5

3. Morino, S., "Recent developments in hybrid structures in Japanresearch, design and construction". Engineering Structures, 20(46), 1998, pp.336-346.

4. Deierlein, G. G., Noguchi, H., "Overview of US-Japan research on the seismic design of composite reinforced concrete and steel moment frame structures". Journal of Structural Engineering, 130(2), 2004, pp.361-367.

5. Li, W., Li, Q., Jiang, W., et al., "Seismic performance of composite reinforced concrete and steel moment frame structures-state-of-theart”. Composites Part B: Engineering, 42(2), 2011, pp.190-206.

6. ASCE Task Committee on Design Criteria for Composite Structures in Steel and Concrete, "Guidelines for design of joints between steel beams and reinforced concrete columns". Journal of Structural Engineering, 120(8), 1994, pp.2330-2357.

7. Nishiyama, I., Kuramoto, H., \& Noguchi, H., "Guidelines: Seimic design of composite reinforced concrete and steel buildings". Journal of Structural Engineering, 130(2), 2004, pp.336-342.

8. Khaloo, A., Doost, R. B., "Seismic performance of precast RC column to steel beam connections with variable joint configurations". Engineering Structures, 160, 2018, pp.408-418.

9. Ling, Y., Xu, J., Guo, Z., Wen, X., "A study on Static behavior of New Reinforced concrete column-steel beam Composite Joints". Journal of Asian Architecture and Building Engineering, 20(1), 2021, pp. 44-60.

10. Griffis, L. G., "Some design considerations for composite-frame structures". Engineering Journal, 23(2), 1986, pp.59-64.

11. Cheng, C. T., \& Chen, C. C., "Seismic behavior of steel beam and reinforced concrete column connections". Journal of Constructional Steel Research, 61(5), 2015, pp.587-606.

12. Kuramoto, H., Nishiyama, I., "Seismic performance and stress transferring mechanism of through-column-type joints for composite reinforced concrete and steel frames". Journal of Structural Engineering, 130(2), 2004, pp. 352-360.
13. Le, D. D., X. H. Nguyen, and Q. H. Nguyen. "Numerical Study on a New Through-Column-Type Joint for RCS Frame". In: Proceedings of the International Conference on Advances in Computational Mechanics, Phu Quoc Island, Vietnam: Springer, 2017, pp.261-272..

14. Nguyen, X. H., Nguyen, Q. H., Le, D. D., et al., "Experimental study on seismic performance of new RCS connection". Structures, 9, 2017, pp.53-62.

15. Doost, R. B., Khaloo, A., "Steel web panel influence on seismic behavior of proposed precast RCS connections". Structures, 32, 2021, pp.87-95.

16. Madandoust, R., Vatandoost, M., Zehtab, M., "Evaluation of seismic behavior improvement in RCS connections". Asian Journal of Civil Engineering, 19(6), 2018, pp. 741-754.

17. Zhao, S. Y., Shi, L., Wang, H. L., "Research status and prospect of reinforced concrete column-steel beam composite joints". North Chian Earthquake Sciences, 35(S1), 2017, pp.1-5(in Chinese).

18. Sheikh, T. M., Deierlein, G. G., Yura, J. A., et al., "Beam-column moment connections for composite frames: Part 1". Journal of Structural Engineering, 115(11), 1989, pp. 2858-2876.

19. Deierlein, G. G., Sheikh, T. M., Yura, J. A., et al., "Beam-column moment connections for composite frames: Part 2". Journal of Structural Engineering, 115(11), 1989, pp. 2877-2896.

20. Kanno, R., "Strength, deformation, and seismic resistance of joints between steel beams and reinforced concrete columns.(Volumes I and II)". Doctoral Dissertation of Cornell University, USA, 1993.

21. Kanno, R., Deierlein, G. G., Deierlein, "Seismic behavior of composite (RCS) beam-column joint subassemblies". Composite Construction in Steel and Concrete III, 1996, pp.236-249

22. Parra-Montesinos, G., Wight, J. K., "Seismic response of exterior RC column-to-steel beam connections". Journal of Structural Engineering, 126(10), 2000, pp.1113-1121

23. Parra-Montesinos, G., Wight, J. K., "Modeling shear behavior of hybrid RCS beam-column connections". Journal of Structural Engineering, 127(1), 2001, pp.3-11.

24. Kanno, R., "Evaluation of existing strength models for RCS joints and consideration toward improved modeling: a study on strength evaluation of RCS joints part 1". Journal of Structural and Construction Engineering , 67(553), 2002, pp.135-142.

25. Hitoshi MORIMOTO, Jun FURUKAWA, Masakazu ICHIKAWA, et al., "Experimental study on strength and deformation capacity of reinforced concrete column and steel beam structure joint of through column type". Journal of Structural and Construction Engineering, 63(513), 1998, pp.181-188. (in Japanese) 
26. Zang, X. L., Zhu, Z. F., "Research status of assembled composite frame joints". China Concrete and Cement Products, 44(4), 2018, pp.69-73.(in Chinese)

27. $\mathrm{Hu}, \mathrm{Y}$. W., "Seismic performance analysis of assembled RCS hybrid frame structure". Master thesis of Xihua University, China, 2017, pp.1-4.(in Chinese)

28. Sum, X. H., Hu, X. Y., Dong, Zhen., et al., "Research, practice and prospect of reinforcement column-steel beam hybrid framed structural systems". Construction Technology, 50(3), 2021, pp.5260.(in Chinese)

29. Guo, Z. P., Zhuo, C., Li, L. M., "Research on seismic behavior of composite joint of prefabricated reinforced concrete column-steel beam". Construction Technology, 49(8), 2020, pp.19-22.(in Chinese)

30. Pan, Z., Si, Q., Zhou, Z., et al., "Experimental and numerical investigations of seismic performance of hybrid joints with bolted connections". Journal of Constructional Steel Research, 138, 2017, pp.867-876.

31. Li, X., Xiao, Y., Mao W. F., et al., "Study on seismic behavior of reinforced concrete column and steel beam joint". Journal of Hunan University (Natural Science Edition), 34(2) 2005, pp.1-5(in Chinese)

32. Mao, W. F., Wu, Y. T., Xiao, Y., et al., "Experimental research on seismic behavior of bolted steel beam to RC column connections". Industrial Construction, 35(11), 2005, pp.1-4 (in Chinese)
33. Lu, T. J., He, Z., Y., Yu, Z. W., et al., "Experimental research on seismic behavior of SC beam to RC column connection". Journal of Building Structures, 29(1), 2008, pp.70-74 (in Chinese)

34. Wang, P., Wang, Z., Pan, J. R. et al., "Experimental study on top and bottom Angle steel beam-column joints with stiffening ribs". Journal of Building Structures, 38(10), 2017, pp. 21-27 (in Chinese)

35. Wang, P., Pan, J., "Experimental and analytical behavior of stiffened angle joints". Steel and Composite Structures, 26(1), 2018, pp. 67-78

36. Wang, P., Pan, J., Wang, Z, et al., "Experimental and numerical investigation of stiffened angle connection in a minor axis". Science Progress, 103(4), 2020, pp.1-27.

37. Pan, J., Wang, P., Zheng, Y., et al., "An analytical study of square CFT columns in bracing connection subjected to axial loading". Advances in Civil Engineering, 2018, doi: 10.1155/2018/8618937.

38. Xu, F. L., Fan, H., Liu, S. B., et al., "Experimental studies on aseismic behavior of connection between concrete-filled steel square tubular column and steel beam". Engineering Mechanics, 25(2), 2008, pp.122-131 (in Chinese)

39. Huo, J. S., "Behavior of steel beam to concrete-filled steel tubular column connections after exposure to fire". Doctoral Dissertation of Fuzhou University, China, 2005, pp.114-119. 